\title{
Postsynaptic EphrinB3 Promotes Shaft Glutamatergic Synapse Formation
}

\author{
Jason Aoto, ${ }^{1}$ Pamela Ting, ${ }^{1}$ Bita Maghsoodi, ${ }^{1}$ Nanjie Xu,${ }^{3}$ Mark Henkemeyer, ${ }^{3}$ and Lu Chen ${ }^{1,2}$ \\ ${ }^{1}$ Department of Molecular and Cell Biology and ${ }^{2}$ Helen Wills Neuroscience Institute, University of California, Berkeley, California 94720-3200, and \\ ${ }^{3}$ Department of Developmental Biology and Kent Waldrep Center for Basic Research on Nerve Growth and Regeneration, University of Texas Southwestern \\ Medical Center, Dallas, Texas 75390
}

\begin{abstract}
Excitatory synapses in the CNS are formed on both dendritic spines and shafts. Recent studies show that the density of shaft synapses may be independently regulated by behavioral learning and the induction of synaptic plasticity, suggesting that distinct mechanisms are involved in regulating these two types of synapses. Although the molecular mechanisms underlying spinogenesis and spine synapse formation are being delineated, those regulating shaft synapses are still unknown. Here, we show that postsynaptic ephrinB3 expression promotes the formation of glutamatergic synapses specifically on the shafts, not on spines. Reducing or increasing postsynaptic ephrinB3 expression selectively decreases or increases shaft synapse density, respectively. In the ephrinB3 knock-out mouse, although spine synapses are normal, shaft synapse formation is reduced in the hippocampus. Overexpression of glutamate receptor-interacting protein 1 (GRIP1) rescues ephrinB3 knockdown phenotype by restoring shaft synapse density. GRIP1 knockdown prevents the increase in shaft synapse density induced by ephrinB3 overexpression. Together, our results reveal a novel mechanism for independent modulation of shaft synapses through ephrinB3 reverse signaling.
\end{abstract}

Key words: ephrin; shaft synapse; reverse signaling; excitatory synapses; hippocampal neurons; GRIP

\section{Introduction}

Although the majority of excitatory synapses are formed on dendritic spines, a subpopulation of glutamatergic terminals in the mammalian CNS makes synaptic contacts on dendritic shafts (Bozhilova-Pastirova and Ovtscharoff, 1996; Fiala et al., 1998; Fiala and Harris, 1999; Anderson and Martin, 2006). In young animals, the percentage of glutamatergic contacts on dendritic shafts can be relatively high ( $\sim 50 \%$ in the rat hippocampus) (Boyer et al., 1998). In adult animals, the abundance of shaft excitatory synapses drops considerably and most glutamatergic synaptic contacts are found on spines. Mechanisms for spine morphogenesis and spine synapse formation have been the focus of intense research because of the unique geometric structure of the spine and its functional implications in synapse-specific plasticity (Dailey and Smith, 1996; Geinisman et al., 1996; Hering and Sheng, 2001; Yuste and Bonhoeffer, 2001, 2004; Ethell and Pasquale, 2005). The developmental downregulation of shaft excitatory synapses, which coincides with the increase in spine synapses, led to the hypothesis that shaft synapses represent a unique

Received Feb. 15, 2007; revised May 11, 2007; accepted June 4, 2007.

This work was supported by National Institutes of Health Grants MH66332 (M.H.) and MH069792 (L.C.), Mabel and Arnold Beckman Foundation, David and Lucile Packard Foundation, and W. M. Keck Foundation (L.C.). We thank Dr. Edward Ziff (New York University, New York, NY) for providing FLAG-GRIP1 CDNAs, Dr. Steve Martin for the pSuper vector (University of California, Berkeley, CA), and Dr. David Raulet for the FITC-conjugated anti-human Fc antibody. We also thank Qi Feng for technical support and members of the Chen Laboratory for discussion and comments on this manuscript.

Correspondence should be addressed to Lu Chen, Department of Molecular and Cell Biology, University of California, 201 LSA, MC 3200, Berkeley, CA 94720-3200. E-mail: luchen@berkeley.edu.

DOI:10.1523/JNEUROSCI.0705-07.2007

Copyright $\odot 2007$ Society for Neuroscience $\quad$ 0270-6474/07/277508-12\$15.00/0 intermediate stage of glutamatergic synapse formation, and they eventually become spine synapses (Fiala et al., 1998; Ethell and Pasquale, 2005). The percentage of shaft glutamatergic synapses in the adult brain can vary from $<10 \%$ in the hippocampus (Harris et al., 1992) to $\sim 30 \%$ in layer I of the somatosensory cortex (Vaughan and Peters, 1973; Trachtenberg et al., 2002). Although shaft synapses found in adult spiny neurons might represent newly formed synapses, several lines of evidence suggest that shaft synapses may have roles other than being precursors of spine synapses. First, it has been shown recently that, in the adult neocortex, spine growth precedes synaptic contact (Knott et al., 2006). Second, the shaft-to-spine synapse formation hypothesis predicts that the curvature of axons should change because of spines emerging from existing shaft synapses. Such changes were not observed (Trachtenberg et al., 2002). Third, increasing evidence has shown that spine and shaft glutamatergic synapses can be differentially regulated by activity, plasticity, and behavioral learning (Geinisman et al., 1996; Helmeke et al., 2001; Zha et al., 2005; Nikolakopoulou et al., 2006). Despite its relatively small population, shaft synapses may be more efficacious, as suggested by both direct measurement of individual postsynaptic density (PSD) size at spine and shaft synapses (Rusakov et al., 1998), and computational modeling (Rall, 1970). The structural differences between shaft and spine synapses may render distinct functions to these two types of synapses. Thus far, research on shaft synapses has been limited to anatomical analysis, primarily because the mechanisms for shaft synapse modulation are completely unknown. Identifying the molecular basis of shaft synapse formation becomes the critical first step to further understanding shaft synapse-related synaptic functions. 
The ephrin/Eph receptor family plays crucial roles in CNS development and plasticity (Klein, 2004). EphrinBs are expressed in discrete subsets of CNS neurons. Presynaptic ephrinBs promote spinogenesis and spine synapse formation through the activation of postsynaptic EphB receptor forward signaling (Dalva et al., 2000; Ethell et al., 2001; Henderson et al., 2001; Penzes et al., 2001; Henkemeyer et al., 2003; Penzes et al., 2003; Moeller et al., 2006; Tremblay et al., 2007). The functions of postsynaptic ephrinBs are not entirely clear. In the hippocampus, ephrinB3 is expressed at a high level in CA1 pyramidal cells (Grunwald et al., 2001). Mice lacking ephrinB3 have abnormal CA1 synaptic functions (Grunwald et al., 2004; Rodenas-Ruano et al., 2006) (but see Armstrong et al., 2006), suggesting that reverse signaling by postsynaptic ephrinB3 is also involved in regulating synapse formation. EphBs and ephrinBs activate different intracellular signaling pathways; therefore, their forward and reverse signaling likely has different regulatory roles on the synapse.

It has been reported that, in hippocampal neuronal cultures, about one-half of the excitatory synapses are formed on dendritic shafts (Boyer et al., 1998). In this study, we take advantage of the hippocampal culture system and examine the roles of postsynaptic ephrinB3 in shaft glutamatergic synapse formation. We show that manipulation of ephrinB3 levels in postsynaptic neurons via overexpression or small interfering RNA (siRNA) knockdown changes glutamatergic synapse density as well as synaptic transmission. These changes, quantified with both presynaptic and postsynaptic markers, occur solely through the adjustment of shaft synapse numbers without detectable changes in spine synapses. We also observed reduced shaft glutamatergic synapse abundance in the CA1 region of the ephrinB3-null mouse. In addition, glutamate receptor-interacting protein 1 (GRIP1), an ephrinB3-interacting postsynaptic density-95/Discs large/zona occludens-1 (PDZ) protein, is required for ephrinB3-mediated shaft synapse formation. Our results identify a novel function of postsynaptic ephrinB3 in synapse formation, and reveal a molecular mechanism by which shaft synapse formation occurs independently from spine synapses.

\section{Materials and Methods}

DNA constructs. Rat ephrinB3 (GenBank accession number EF566467) was amplified from Sprague Dawley rat whole-brain cDNA using the following primers: ephrinB3, forward, $5^{\prime}$-atctgctagcatgggggccccccattttgg- $3^{\prime}$; and ephrinB3, reverse, $5^{\prime}$-cgtgagcggccgctcataccttgtaatagat $-3^{\prime}$, and inserted into the NheI/NotI restriction sites of pCI-Neo (Promega, Madison, WI). To generate cyan fluorescent protein (CFP)-ephrinB3, cyan fluorescent protein was inserted after the ephrinB3 leader peptide. The sequence junction is as follows: LLGFAGL CFP VSGLSLE (ephrinB3 sequence underlined). Rat ephrinB2 was similarly cloned and constructed. Rat CFP-ephrinB3- $\triangle$ PDZ was generated the same way but lacked the last four amino acids. The sequence of the truncated $C$ terminus was as follows: PQSPPNI. To generate siRNA resistant rat ephrinB3, a silent mutation (Y338) was introduced by PCR. FLAG-tagged GRIP1 (FLAGGRIP1) was a generous gift from Dr. Edward Ziff (New York University, New York, NY). Rat EphB2 clone was purchased from Open Biosystems (Huntsville, AL).

siRNA design. The siRNA constructs were inserted into pSuper-Retrogreen fluorescent protein (GFP; Oligogene, Seattle, WA) according to the manufacturer's protocol. EphrinB3 siRNA was directed against bases $998-1016$ of rat ephrinB3. The sense sequence was as follows: $5^{\prime}$-ctccgaacatctattacaa- $3^{\prime}$; and the antisense sequence was as follows: $5^{\prime}$ gaggcttgtagataatgtt-3'. Rat GRIP1 (NM_032069.1) siRNA was designed according to the sequence provided by Open Biosystems and targeted nucleotides 1079-1097.

Antibodies. The following mouse monoclonal antibodies were used: anti-FLAG M2 (1:1000; Sigma, St. Louis, MO), anti-glutamic acid decar- boxylase 6 (GAD-6; 1:25; Developmental Studies Hybridoma Bank, Iowa City, IA), anti-GFP [immunocytochemistry (ICC), 1:500; Millipore, Temecula, CA], and anti-PSD-95 [Western blot (WB), 1:2000; ICC, 1:200; Affinity BioReagents, Golden, CO]. The following polyclonal antibodies were used: rabbit anti-GFP (WB, 1:5000; ICC, 1:100; Abcam, Cambridge, MA), rabbit anti-vesicular glutamate transporter 2 (VGluT2) (1:1000; Abcam), guinea pig anti-VGluT1 (1:500; Millipore), and rabbit antiGRIP-1 (WB, $2 \mu \mathrm{g} / \mathrm{ml}$; ICC, $2 \mu \mathrm{g} / \mathrm{ml}$; Upstate Biotechnology, Charlottesville, VA). The following goat polyclonal secondary antibodies, from Jackson ImmunoResearch (West Grove, PA), were used: anti-rabbit cyanine 2 (Cy2) (1:100), anti-mouse Cy2 (1:100), anti-guinea pig Cy3 (1: 100), anti-rabbit Cy3 (1:100), anti-mouse Cy3 (1:100), anti-guinea pig Cy5 (1:100), anti-mouse Cy5 (1:100), and anti-rabbit horseradish peroxidase (HRP) (1:50,000).

Membrane clustering. Membrane clustering experiments were performed as previously described (Bruckner et al., 1999). Briefly, EphB2-Fc (R\&D Systems, Minneapolis, MN) was preclustered with an anti-human Fc antibody conjugated to FITC at room temperature for $1 \mathrm{~h}$. Neurons were treated with the preclustered EphB2-Fc $(4 \mu \mathrm{g} / \mathrm{ml})$ for $45 \mathrm{~min}$ at $12^{\circ} \mathrm{C}$. In the human embryonic kidney 293 (HEK293) cell experiment, culture medium was replaced with serum-free DMEM immediately before EphB2-Fc application, and EphB2-Fc was applied directly without preclustering. Cells were immediately fixed and prepared for immunocytochemistry as described in the supplemental material (available at www.jneurosci.org).

Western blot. Twenty-four hours before transfection, $5 \times 10^{5}$ HEK293 cells per well were seeded in six-well plates. To confirm RNA interference (RNAi) efficacy, siRNA constructs were cotransfected with appropriate target constructs in a 1:1 ratio. Twenty-four hours after transfection, cells were lysed in lysis buffer (50 mм Tris, pH 7.5, $150 \mathrm{~mm} \mathrm{NaCl}, 5 \mathrm{~mm}$ EDTA, $1 \%$ Triton X-100, $10 \mu \mathrm{g} / \mathrm{ml}$ aprotinin, $1 \mathrm{~mm}$ PMSF) at a concentration of $1 \times 10^{4}$ cells per microliter. The lysates were then passed through a 25.5 gauge needle and run on $10 \%$ SDS polyacrylamide gels. Proteins were transferred to Immobilon-P polyvinylidene difluoride membranes (Millipore), incubated in TBST $(0.2 \%)$ with $5 \%$ nonfat milk for $1 \mathrm{~h}$, and immunoblotted as per standard protocols. Detection used a HRP secondary followed by enhanced chemiluminescence (Pierce, Rockford, IL).

Cell cultures, transfection, and immunolabeling. Primary hippocampal cultures were prepared from the brains of rats at embryonic days $18-22$ and plated at a density of $100 \times 10^{3}$ cells $/ \mathrm{ml}$. Cultures were maintained in serum-free Neurobasal medium supplemented with B-27 and Glutamax (Invitrogen, Grand Island, NY) for 2 weeks in vitro (Nam and Chen, 2005). HEK293 cells were cultured in DMEM supplemented with $10 \%$ fetal bovine serum (Invitrogen). Nine to $11 \mathrm{~d}$ in vitro (DIV) neurons were transfected by using Lipofectamine 2000 (Invitrogen) with a protocol described previously (Nam and Chen, 2005). HEK293 cells were transfected using HEKfectin (Bio-Rad, Hercules, CA) according to the manufacturer's instructions. For coculture experiments, neurons and HEK293 cells were initially cultured separately and were transfected on the same day. One day after transfection, HEK293 cells were resuspended and plated onto neuronal cultures.

Immunocytochemistry was performed on cultures fixed with $2 \%$ paraformaldehyde (15 min; room temperature) and washed with PBS containing $0.3 \%$ Triton X-100 before incubation with primary and secondary antibodies.

EM analysis. Five-month-old mice were anesthetized with intraperitoneal injection of $0.2-0.3 \mathrm{ml}$ of ketamine/xylazine mixture containing ketamine-HCl (Ketaset), xylazine (X-Ject-SA), and PBS (9:1:10) and perfused with $2 \%$ paraformaldehyde, $2.5 \%$ glutaraldehyde in $0.1 \mathrm{M}$ cacodylate buffer with $2 \mathrm{mM} \mathrm{CaCl}_{2}$ and $4 \mathrm{~mm} \mathrm{MgCl}_{2}$. Brains were postfixed in the same solution for another $3-5 \mathrm{~d}$ at $4^{\circ} \mathrm{C}$. Hippocampal CA1 regions were microdissected and fixed in $1 \% \mathrm{OsO}_{4}$ and $1.5 \% \mathrm{~K}_{4} \mathrm{Fe}(\mathrm{CN})_{6}$ for $1 \mathrm{~h}$ at $4^{\circ} \mathrm{C}$. After thorough rinse, tissues were incubated in $1 \%$ aqueous uranyl acetate for an hour at room temperature, and were subsequently dehydrated and embedded in LR White resin and hardened at $50^{\circ} \mathrm{C}$ overnight. Thin $(50-70 \mathrm{~nm})$ sections were cut and mounted on formvar-coated slot grids (Ted Pella, Redding, CA). Sections were stained with $1 \%$ uranyl acetate, followed by Reynolds lead citrate for 5 min each. Sections were imaged, 
A
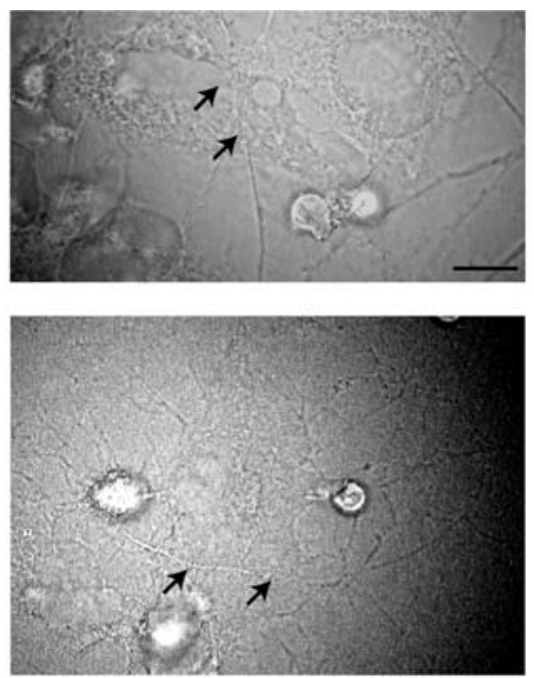
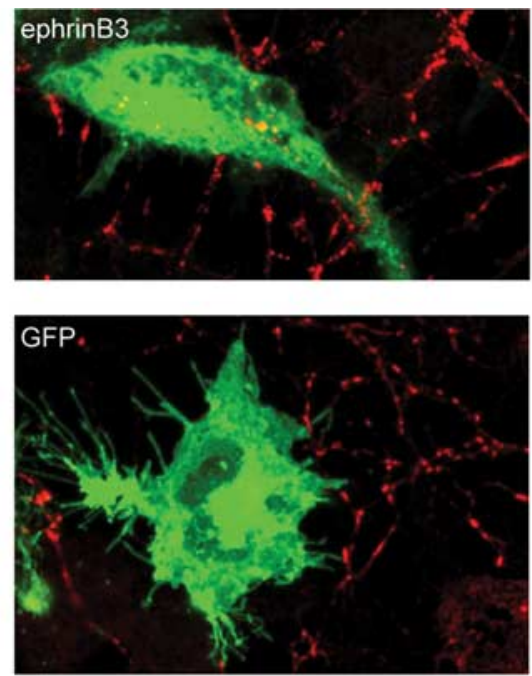
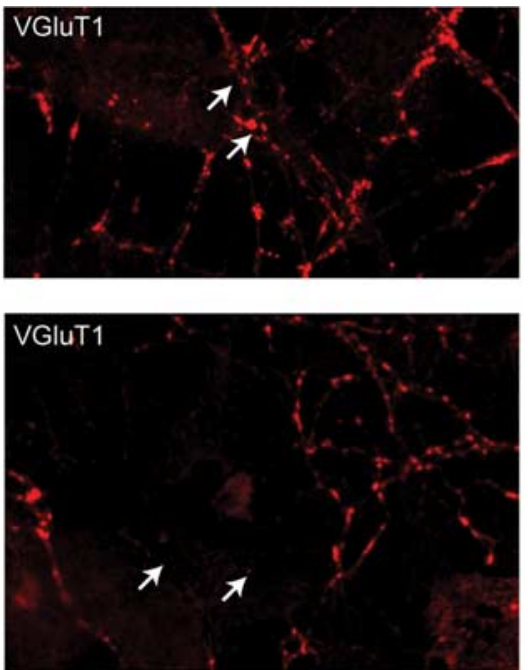

B

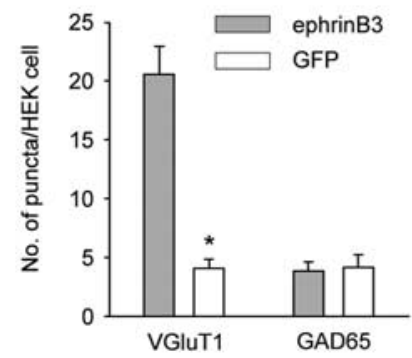

C

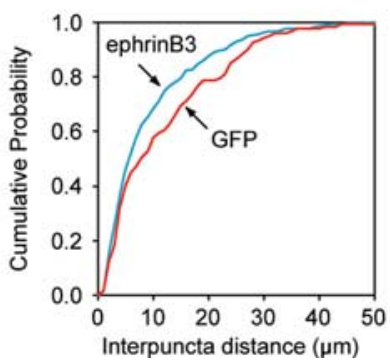

D

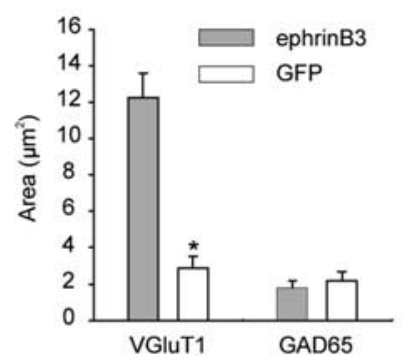

E

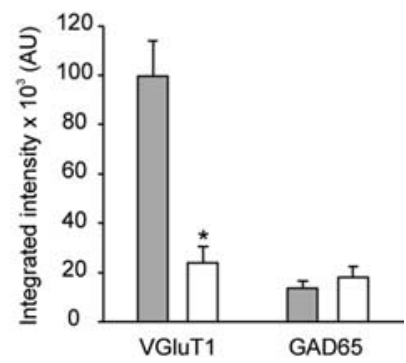

Figure 1. Expression of ephrinB3 in HEK293 cells clusters glutamate synaptic vesicles. $\boldsymbol{A}$, The ephrinB3-or GFP-expressing HEK293 cells were cocultured with 10 -12 DIV hippocampal neurons for $2 \mathrm{~d}$. VGluT1 staining revealed formation of glutamatergic presynaptic terminals in axons crossing HEK293 cells expressing ephrinB3, but not those expressing GFP. Axons are highlighted by arrows in the differential interference contrast pictures. Scale bar, $10 \mu \mathrm{m}$. B, Number of VGluT1 puncta in axons crossing ephrinB3-expressing HEK293 cells was greater than in those that contact GFP-expressing HEK293 cells (ephrinB3, $n=17 ; \mathrm{GFP}, n=33$; $^{*} p<1 \times 10^{-10}$ ). No significant increase in GAD65 clustering was induced by ephrinB3 (ephrinB3, $n=17 ;$ GFP, $n=22 ; p>0.5$ ). $\boldsymbol{C}$, The VGluT1 interpuncta distance was significantly larger in axons contacting GFP-expressing HEK293 cells compared with ephrinB3-expressing cells ( $p<0.05$ ). $\boldsymbol{D}, \boldsymbol{E}$, Total area and integrated intensity of VGluT1 puncta for axons contacting ephrinB3-expressing HEK293 cells were greater than those crossing GFP-expressing cells (ephrinB3, $n=17$; GFP, $n=33$; ${ }^{*} p<1 \times 10^{-6}$ ). No significant change in GAD65 signal was induced by ephrinB3 expression (ephrinB3, $n=17 ; \mathrm{GFP}, n=22 ; p>0.5$ ). All error bars indicate SEM.

blind to the animal genotypes, with a JOEL transmission electron microscope.

Electrophysiology. Whole-cell patch-clamp recordings were made at room temperature from 12-14 DIV cultured neurons, with 4-6 $\mathrm{M} \Omega$ patch pipettes filled with an internal solution containing the following (in mM): $120 \mathrm{CsCl}, 2 \mathrm{MgCl}_{2}, 5$ EGTA, 10 HEPES, $0.3 \mathrm{Na}_{3}$-GTP, $4 \mathrm{Na}_{2}$-ATP, pH 7.35. Cultures were continuously superfused with external solution (in mM: $100 \mathrm{NaCl}, 26 \mathrm{NaHCO}_{3}, 2.5 \mathrm{KCl}, 11$ glucose, 2.5 $\mathrm{CaCl}_{2}, 1.3 \mathrm{MgSO}_{4}, 1.0 \mathrm{NaH}_{2} \mathrm{PO}_{4}$ ). For miniature EPSC (mEPSC) recording, tetrodotoxin $(1 \mu \mathrm{M})$ and picrotoxin $(100 \mu \mathrm{M})$ were included in the external saline. For miniature IPSC (mIPSC) recording, tetrodotoxin (1 $\mu \mathrm{M}), \mathrm{CNQX}(10 \mathrm{~mm})$, and APV $(100 \mathrm{~mm})$ were applied to the external saline. Cells were held at $-60 \mathrm{mV}$. Miniature responses were analyzed with Mini Analysis Program from Synaptosoft (Decatur, GA).

For paired recordings, presynaptic neurons were recorded in wholecell current-clamp mode using electrodes filled with a solution of the following (in mM): $120 \mathrm{~K}$-gluconate, $10 \mathrm{HEPES}, 1 \mathrm{EGTA}, 4 \mathrm{Mg}$-ATP, and $0.3 \mathrm{Na}_{3}-\mathrm{GTP}, \mathrm{pH}$ 7.35. A constant hyperpolarizing current was used to maintain a resting potential of -60 to $-70 \mathrm{mV}$. Single action potentials were elicited with $5 \mathrm{~ms}$ current injections sufficient to bring the cell just above threshold.

Image acquisition and quantification. For fluorescent image analysis, cells were chosen randomly from three or more independent batches of cultures with four or more coverslips per batch for each construct. Fluorescent images were acquired at room temperature with an Olympus (Tokyo, Japan) FV1000 BX61WI laser-scanning confocal microscope, using an Olympus Plan Apochromat $60 \times$ oil objective [numerical aperture (NA), 1.42; working distance (WD), 0.15] or an Olympus U-Plan Apochromat $100 \times$ oil objective (NA, 1.40; WD, 0.12) with sequential acquisition setting at $1024 \times 1024$ pixel resolutions. Laser power and photomultipliers were set such that no detectable bleedthrough occurred between different channels. Digital images of the cells were captured with Fluoview Imaging software (Olympus). Eight to 10 sections were taken from top to bottom of the specimen, and brightest point projections were made. Images for the same experiments were taken using identical settings for laser power, photomultiplier gain, and offset. These settings were chosen such that the pixel intensities for the brightest samples were just below saturation, with the exception that when contours of the cell or contours of the neuronal processes have to be clearly determined, signals from certain areas (center of the HEK cell body or soma of the neurons) were saturated to obtain clear signals from the periphery of the cell body or neuronal dendrites. Quantification of fluorescent signals of immunostained proteins was performed as described (Nam and Chen, 2005). Briefly, images collected using identical confocal settings were thresholded by intensity to exclude the diffuse/intracellular pool, and puncta were quantified by counting the number of thresholded areas of sizes between 0.25 and $4 \mu \mathrm{m}^{2}$. Results were averaged for at least 15 images per condition and the mean and SE were calculated. Puncta distance was determined by averaging the distance between the center of each punctum and its nearest neighbor on the same dendrite. Image quantification was performed by experienced investigators who were blind to the experimental conditions. 


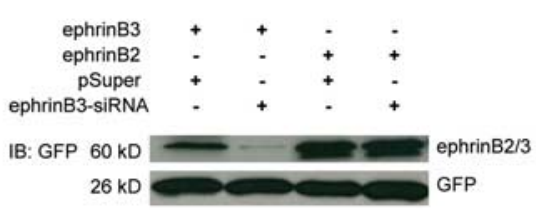

C
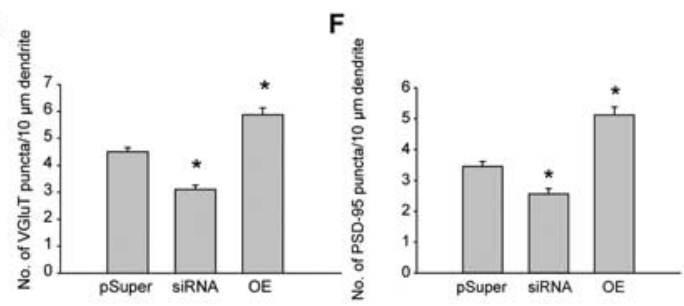

D
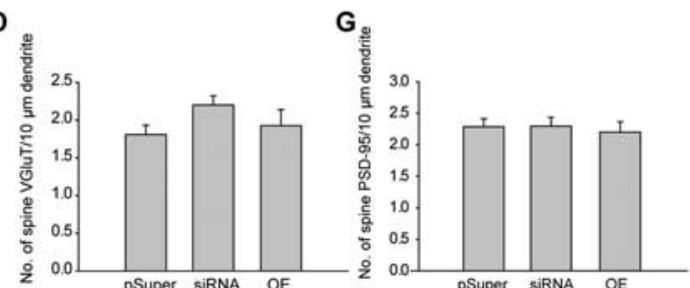

E
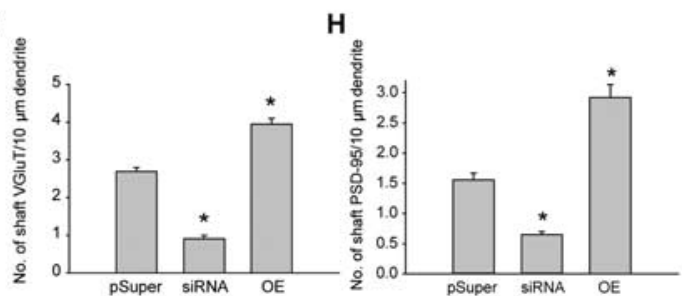

B
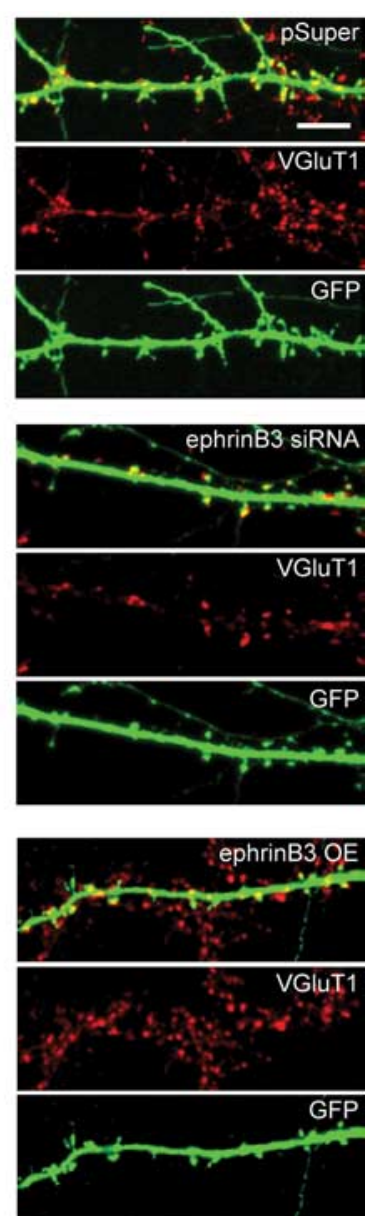

Figure 2. Selective modulation of shaft synapses by ephrinB3. A, Efficiency and specificity of ephrinB3-siRNA. HEK293 cells were transfected with pSuper empty vector or pSuper-based construct targeting rat ephrinB3, together with cDNAs expressing CFP-ephrinB3 or CFP-ephrinB2, and were immunoblotted for CFP with a GFP antibody. The bands found at $\sim 60 \mathrm{kDa}$ represent (FP-tagged ephrinBs. GFP expression (the $26 \mathrm{kDa}$ band) driven by a second promoter in pSuper vector was used as the loading control. B, Excitatory (VGluT1-positive) synapse density was increased by postsynaptic ephrinB3 overexpression, and reduced by eprhinB3 knockdown. Scale bar, $10 \mu \mathrm{m}$. $\boldsymbol{C}-\boldsymbol{E}$, Synapse density quantified with the excitatory presynaptic marker VGluT1. C, Total VGluT1 density on dendrites of pSuper-, ephrinB3-siRNA, or ephrinB3-transfected (OE, overexpression) neurons. RNAi significantly reduced excitatory synapse density, whereas ephrinB3 overexpression increased it (pSuper, $n=18$ cells; RNAi, $n=18$ cells; OE, $n=22$ cells; 3 branches/cell; $\left.{ }^{*} p<1 \times 10^{-5}\right)$. D , EphrinB3 knockdown slightly increased spine VGluT1 density $(p=0.04)$, and ephrinB3 overexpression had no effect on VGluT1 density $(p>0.6)$. $\boldsymbol{E}$, The density of VGluT1 puncta that were on the shaft were dramatically reduced by RNAi of ephrinB3, and increased by postsynaptic ephrinB3 overexpression $\left({ }^{*} p<0.005\right)$. $\boldsymbol{F}-\boldsymbol{H}$, Synapse density quantified with excitatory postsynaptic marker PSD-95. F, Similar to results obtained with VGluT1 staining, total PSD-95 puncta density was reduced by ephrinB3-siRNA and increased by ephrinB3 overexpression ( $n=15$ cells per group; 3 branches/cell; * $p<0.05$ ). G, PSD-95 density in spines was not affected ( $p>0.5$ ). $\boldsymbol{H}$, PSD-95 density in shafts was greatly reduced by ephrinB3-siRNA $\left(p<10^{-12}\right.$ ) and increased by ephrinB3 overexpression $(p<0.0005)$. All error bars indicate SEM.

For the neuron-HEK293 coculture assay, because our neuronal culture is plated at high density, and $>80 \%$ HEK cells show significant contact with crossing axons under phase contrast after $1 \mathrm{~d}$ of coplating, transfected HEK293 cells were chosen randomly from areas of dense neural networks. For each presynaptic protein cluster, the area and integrated intensity were measured. Puncta distance was determined by measuring the distance between the center of each punctum and its nearest neighbor on the same HEK cells.

For spine and shaft synapse density analysis, dendritic segments were chosen randomly and their lengths were measured in two-dimensional projection of three-dimensional image stacks. Spines were identified with Fluoview program by examining the three-dimensional stacks and were defined as any protrusions from the dendritic shaft $<8 \mu \mathrm{m}$ in length. The number of VGluT1 puncta on spine and shaft synapses of the selected dendritic segment is determined by measuring VGluT1 puncta that are either partially overlapping or immediately juxaposed to the GFP-positive shaft or spine. Any VGluT1 puncta that are nearby but not
VGluT1

touching the GFP-positive dendrite are not included. The number of PSD-95 puncta on spine and shaft synapse of the selected dendritic segment is determined by measuring PSD-95 puncta that have at least 4 pixels overlaping with the GFP-positive dendrite.

Statistical analysis. Single-factor ANOVA was used for statistical analysis (unless otherwise stated in figure legends). Values are presented as mean $\pm \mathrm{SEM}$ in figures.

\section{Results}

Synaptogenic activity of postsynaptic ephrinB3

Many synaptic adhesion molecules that promote synaptogenesis, such as neuroligins and synCAM (synaptic cell adhesion molecule), are capable of inducing synaptic vesicle clustering in contacting axons when expressed in heterologous cells (Scheiffele et al., 2000; Biederer et al., 2002; Graf et al., 2004). To investigate whether postsynaptic ephrinB3 has synaptogenic activity, we plated ephrinB3-transfected HEK293 cells together with cultured neurons. One to $2 \mathrm{~d}$ after coplating, the cultures were stained for VGluT1 and GAD65, presynaptic markers for excitatory and inhibitory synaptic terminals, respectively. An accumulation of VGluT1 signal was observed in axons crossing ephrinB3-expressing HEK293 cells, but not in those that contact GFP-expressing cells (Figs. $1 A, B$ ). In contrast to endogenous synaptic clusters, the induced clusters of VGluT1 on HEK293 cells lacked PSD-95 immunoreactivity (supplemental Fig. 1, available at www.jneurosci.org as supplemental material). Neither ephrinB3 nor GFP-expressing HEK293 cells induced significant GAD65 clustering in crossing axons (Fig. $1 B)$. This selective increase in excitatory presynaptic terminal density induced by ephrinB3-expressing HEK293 cells was further supported by significant increases in VGluT1 puncta density, total area, and integrated intensity (area $\times$ intensity) for HEK293 cells expressing ephrinB3, but not for those that express GFP (Fig. 1C-E).

\section{EphrinB3 selectively modulates shaft synapse density}

We knocked down endogenous ephrinB3 in hippocampal neurons at 9 DIV by plasmid (pSuper)-based RNA interference using ephrinB3-siRNA (for knockdown efficiency tested in HEK293 cells, see Fig. 2A). Four days after the ephrinB3-siRNA transfection, we observed a significant reduction in the density of presynaptic VGluT1 puncta formed on transfected postsynaptic neurons. In contrast, the density of VGluT1 puncta on ephrinB3overexpressing neurons was significantly increased (Fig. $2 B, C$ ). Most importantly, these changes in VGluT1 signals occurred specifically at shaft synapses (Fig. 2E). As shown in Figure 2D, ephrinB3 overexpression did not alter spine synapse density, 
whereas ephrinB3-siRNA transfection slightly increased spine synapse density $(p=0.04)$. The distributions of PSD-95 corroborated the findings with VGluT1 staining. PSD-95 puncta density was reduced by knocking down endogenous ephrinB3 and increased by ephrinB3 overexpression (Fig. 2 F; supplemental Fig. 2, available at www.jneurosci.org as supplemental material). These changes were again attributable to a selective modification of PSD-95 puncta density on the shafts, not in the spines (Fig. 2G,H).

We also compared the properties of individual VGluT1 puncta formed on neurons expressing pSuper empty vector, ephrinB3-siRNA, or ephrinB3. The size and intensity of VGluT1 puncta on ephrinB3-overexpressing neurons were not different from those on pSuper-expressing neurons $(p>0.1)$, and these parameters were slightly increased on ephrinB3siRNA-expressing neurons ( $p=0.02$ for intensity and $p=0.06$ for size) (supplemental Fig. 3, available at www. jneurosci.org as supplemental material). These increases in VGluT1 puncta size and intensity indicate that the reduction in shaft synapse density induced by ephrinB3-siRNA was not attributable to a global weakening of all existing synapses.

Because shaft glutamatergic synapses are more abundant in cultures than in vivo (Boyer et al., 1998), we also examined excitatory synapse formation in the CA1 region of adult wild-type (WT) and ephrinB3-null mice (Yokoyama et al., 2001) with EM. We first quantified excitatory synapse density with micrographs taken at low magnifications $(10,000-15,000 \times)$ (Fig. $3 A$ ) and measured PSD width under higher magnifications $(20,000-40,000 \times)$ (Fig. 3B). Neither the density nor the size was significantly changed in the ephrinB3-null mouse (synapse density: two animals per group, WT, $1.01 \pm 0.06$ per $\mu \mathrm{m}^{3}, n=43$ micrographs; ephrinB3 ${ }^{-1-}$, $0.91 \pm 0.07$ per $\mu \mathrm{m}^{3}, n=34$ micrographs; $p>0.3$; PSD size: two animals per group, WT, $0.168 \pm 0.003 \mu \mathrm{m}, n=438$ PSDs; ephrinB3 ${ }^{-l-}, 0.175 \pm 0.003, n=562$ PSDs; $p>0.05$ ), which is consistent with their normal basal synaptic transmission (Grunwald et al., 2004). We then quantified the percentage of excitatory synapses made on dendritic shafts (Fig. 3C). Consistent with previously reported results, a low abundance of shaft glutamatergic synapses $(7.75 \%)$ was observed in stratum radiatum and stratum lacunosum moleculare (Table 1) in WT animals. A significant reduction of shaft synapse abundance to $3.38 \%$ was found in ephrinB3-null animals (Table 1), suggesting that ephrinB3 plays a role in shaft glutamatergic synapse formation in vivo.

\section{EphrinB3 enhances excitatory synaptic transmission by promoting synapse formation}

To examine whether shaft synapses induced by acute ephrinB3 overexpression are functional, we recorded mEPSCs in 13 DIV hippocampal neurons transfected with either GFP or ephrinB3. Only neurons that had spines and exhibited pyramidal neuron morphology were recorded from to maintain the homogeneity of
Table 1. Reduced shaft synapse abundance in the hippocampal CA1 region of the ephrinB3-null mouse

\begin{tabular}{lccc}
\hline & $\begin{array}{l}\text { No. of total excitatory } \\
\text { synapses examined }\end{array}$ & $\begin{array}{l}\text { No. of shaft excitatory } \\
\text { synapses found }\end{array}$ & Shaft synapses (\%) \\
\hline Wild type & 696 & 54 & 7.75 \\
EphrinB3 $^{-1-}$ & 739 & 25 & $3.38^{*}$ \\
\hline
\end{tabular}

Data are pooled from two animals for each group. ${ }^{*} p<0.0005, \chi^{2}$ test.

the neuronal populations studied. The average mEPSC frequency was significantly increased in these neurons, whereas the average mEPSC amplitude was not affected (Fig. 4A). This increase in synaptic transmission is selective for excitatory synapses, because neither the frequency nor the amplitude of mIPSCs was affected by ephrinB3 overexpression (Fig. 4B). Although EphB receptors have been reported to play important roles in spine morphogenesis, excitatory synapse formation, and synaptic plasticity in the CNS (Dalva et al., 2000; Ethell et al., 2001; Henderson et al., 2001; Henkemeyer et al., 2003), in our culture system, overexpressing EphB2 in postsynaptic neurons at this developmental stage did not change basal synaptic transmission (Fig. $4 A$ ).

The observed increase in mEPSC frequency could be attributable to an increase in presynaptic release probability and/or an increase in the number of synapses. We measured synaptic paired-pulse response ratios (PPRs) to assess presynaptic release probability (Katz and Miledi, 1968; Zucker and Regehr, 2002). Whole-cell patch-clamp recordings were made on pairs of synaptically connected cultured hippocampal neurons. Two action 
A
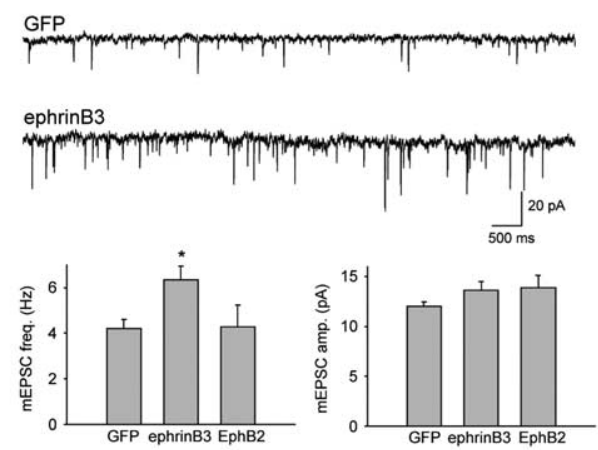

C
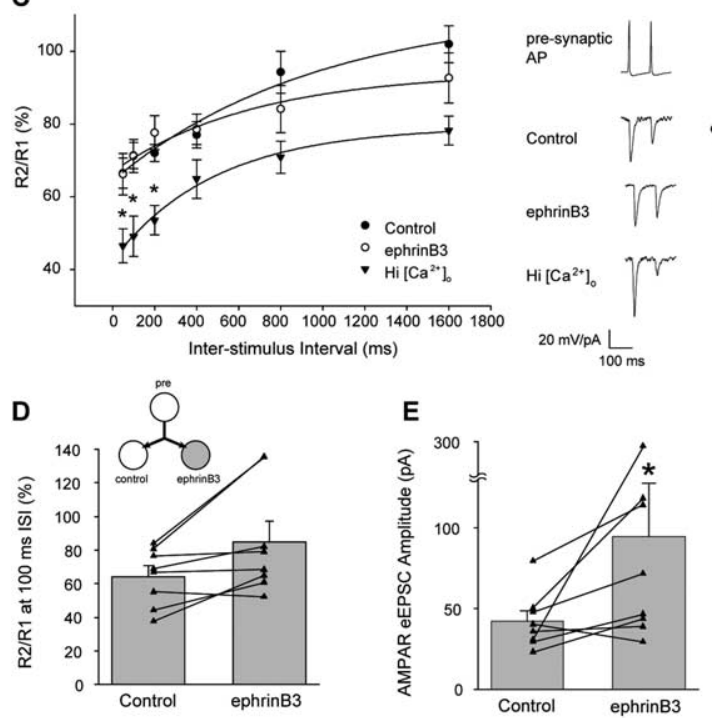

G

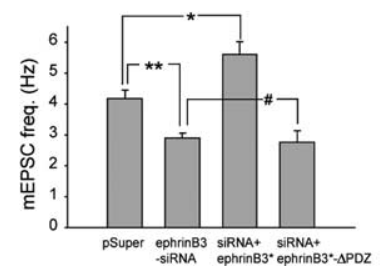

Figure 4. Postsynaptic ephrinB3 expression increases excitatory synaptic function. $A$, EphrinB3 overexpression for $1 \mathrm{~d}$ increased mEPSC frequency $\left(n=26\right.$ for each group; $\left.{ }^{*} p<0.01\right)$ but not their amplitude $(p>0.1)$. EphB2 overexpression did not affect excitatory synaptic transmission ( $n=29$; frequency, $p>0.5$; amplitude, $p>0.09)$. $\boldsymbol{B}$, 0verexpression of ephrinB3 did not affect frequency or amplitude of mIPSCs (GFP, $n=25$; ephrinB3, $n=22$; frequency, $p>0.1$; amplitude, $p>0.5$ ). C, The PPRs of evoked responses (R2/R1) at various intervals were measured between two synaptically connected hippocampal neurons with paired whole-cell patch-clamp recording. Increasing external calcium concentration significantly reduced PPR (control, $n=14$; high $\left.\mathrm{Ca}^{2+}, n=9 ;{ }^{*} p<0.005\right)$. Postsynaptic expression of ephrinB3 did not significantly change the PPR $(n=14 ; p>0.5)$. Representative traces (average from 5 trials) under each recording condition are shown at the right. $\boldsymbol{D}, \boldsymbol{E}$, Direct comparison of presynaptic release properties in a triplet mode. $\boldsymbol{D}$, The schematic on top depicts the triplet-recording mode in which two postsynaptic cells, one untransfected and the other overexpressing ephrinB3, share one presynaptic neuron. Postsynaptic ephrinB3 overexpression did not cause reduction in the PPR ( $n=8$ triplet pairs; $p>0.1$, paired $t$ test). $\boldsymbol{E}$, However, a significant increase in evoked response amplitude was induced by ephrinB3 overexpression ( ${ }^{*} p<0.05$, paired $t$ test). $\boldsymbol{F}$, Two CFP-ephrinB3 constructs, one full-length bearing a silent mutation (ephrinB3*) and the other with a PDZ-binding domain deletion (ephrinB3*- $P D Z$ ), are resistant to ephrinB3-siRNA. G, AMPA receptor-mediated mEPSC frequency was reduced by ephrinB3 knockdown (pSuper, $n=$ $24 ;$ siRNA, $\left.n=30 ;{ }^{* *} p<1 \times 10^{-4}\right)$. This reduction was fully rescued by coexpression of the mutant full-length ephrinB $3^{*}(n=$ $\left.30 ;{ }^{*} p<0.01\right)$, but not by coexpression of the ephrinB3* $-\triangle \mathrm{PDZ}\left(n=26 ;{ }^{*} p>0.5\right)$. All error bars indicate SEM.

potentials were elicited by brief $5 \mathrm{~ms}$ current injections in the presynaptic neurons, and the PPR of evoked EPSCs was measured in postsynaptic neurons at various interstimulus intervals. Raising the external $\mathrm{Ca}^{2+}$ concentration from 2.5 to $4.0 \mathrm{~mm}$, which increases transmitter release probability and served as a positive control, significantly reduced the PPR (Fig. 4C). In contrast, overexpression of ephrinB3 in the postsynaptic neurons did not significantly change the PPR (Fig. 4C). A subset of neurons were recorded in a "triplet" mode, which allowed us to directly compare the evoked EPSCs between one presynaptic neuron and two of its postsynaptic targets, one control and the other overexpressing ephrinB3. In these triplet neurons, ephrinB3 overex- pression again did not change the PPR, but significantly increased the amplitude of evoked EPSCs (Fig. 4D,E). This enhancement in evoked EPSC amplitude in the absence of a PPR reduction, together with the increased miniature EPSC frequency but not amplitude (Fig. $4 A$ ), confirms that postsynaptic ephrinB3 promotes synapse formation.

In neurons expressing ephrinB3siRNA, we observed reduced mEPSC frequency (Fig. 4G), but not amplitude (data not shown). We attempted to rescue this ephrinB3-siRNA phenotype using two ephrinB3 constructs resistant to ephrinB3-siRNA (a full-length ephrinB3 ${ }^{\star}$ and a PDZ-binding motif deletion mutant ephrinB3*- ${ }^{*}$ PDZ) (Fig. $4 F$ ). Interestingly, the ephrinB3-siRNA phenotype was successfully rescued by the full-length ephrinB3*, but not the ephrinB3 ${ }^{*}-\Delta$ PDZ (Fig. 4G), suggesting that synaptic PDZ proteins may be involved in ephrinB3mediated shaft synapse formation.

\section{EphrinB3 interacts and coclusters with GRIP1}

GRIP, a synaptic PDZ protein that directly binds to AMPA receptors (Dong et al., 1997), interacts with ephrinB3 (Bruckner et al., 1999) through PDZ domain interactions, and therefore may be involved in the regulation of shaft synapses by ephrinB3. To determine whether these two proteins interact in neurons, we preclustered EphB2-Fc with a FITC-conjugated secondary antibody and applied it exogenously to cultured hippocampal neurons. Clusters of GRIP1 immunostaining were found highly colocalized with EphB2-Fc (Fig. 5A,B). To further test whether the recruitment of GRIP to EphB2-Fc clusters is mediated by endogenous ephrinB3, we transfected neurons with ephrinB3- $\triangle$ PDZ. Application of EphB2-Fc failed to recruit GRIP1 in neurons overexpressing ephrinB3- $\Delta \mathrm{PDZ}$ (colocalization between EphB2-Fc and GRIP-1 signals dropped from $49.61 \pm$ $3.43 \%$ in untransfected neurons to $15.03 \pm 1.31 \%$ in ephrinB3- $\Delta$ PDZ-transfected neurons; $n=24$ dendrites from eight neurons per group; $p<1 \times 10^{-10}$ ) (Fig. $5 A, B$ ), suggesting that ephrinB3- $\Delta$ PDZ, acting in a dominant-negative manner, sequestered EphB2-Fc and prevented the recruitment of GRIP1 to EphB2-Fc clusters. Hampered by the lack of a specific ephrinB3 antibody (Armstrong et al., 2006), we were unable to directly monitor endogenous ephrinB3 localization in the neurons. However, we observed similar coclustering of CFP-ephrinB3 and FLAG-GRIP1 in HEK293 cells after EphB2-Fc application (Fig. 5C). Such coclustering was not observed when CFP-ephrinB3- $\triangle \mathrm{PDZ}$ and FLAG-GRIP1 were coexpressed (Fig. $5 C$ ). The lack of apparent 
clustering of CFP-ephrinB3- $\Delta$ PDZ by EphB2-Fc also suggest that multimerization of GRIP1 (Im et al., 2003) may be required to induce large clusters of ephrinB3 and EphBs.

\section{Manipulation of ephrinB3 expression levels changes GRIP1 distributions} GRIP1 has been shown to cluster in both dendritic spines and shafts (Dong et al., 1999). We wondered whether changing the ephrinB3 expression level could affect the distributions of GRIP1 between dendritic spines and shafts. Mean fluorescence intensities of GRIP1 immunoreactivity in dendritic shafts and spines from the same branches were quantified. Compared with control neurons, ephrinB3-expressing neurons retained more GRIP1 in the shaft, indicated by a significant reduction of the spine/shaft signal ratio (Fig. 6A). Conversely, ephrinB3 knockdown enhanced the localization of GRIP1 in the spines (Fig. 6A). The relative spine-to-shaft distribution of another postsynaptic density protein PSD-95 was not significantly shifted by ephrinB3 expression level (supplemental Fig. 4, available at www. jneurosci.org as supplemental material). Because GRIP1 is localized at excitatory as well as inhibitory synapses (Dong et al., 1999), we further examined the effects of ephrinB3 on GRIP1 distributions specifically at excitatory synapses, using VGluT1 as an excitatory synapse marker. In 14 DIV cultured hippocampal neurons, $\sim 67 \%$ of spine synapses contain GRIP1. Overexpression of ephrinB3 significantly reduced GRIP1 signal intensity in spines (Fig. $6 B, C)$, although, in most cases, GRIP1 was not completely removed from these spines. The proportion of spine synapses containing GRIP1 was slightly reduced (from 67 to $60 \%$; not statistically significant). In contrast, ephrinB3-siRNA significantly increased the proportion of GRIP1-positive spines to $76 \%$ (Fig. 6C). Given these results, if GRIP1 levels in spines were important for spine synapse formation or its function, we would expect to find altered spine synapse density or altered mEPSC amplitude in ephrinB3- and ephrinB3-siRNAtransfected neurons. The absence of these changes indicates that spine synapse function is uncorrelated with GRIP1 localization in spines. GRIP1 was also found at $\sim 76 \%$ of shaft glutamatergic synapses (Fig. $6 B, C$ ). Although elevating or knocking down ephrinB3 levels significantly changed the shaft excitatory synapse density, the proportion of GRIP1-positive shaft synapses remained the same under these conditions (Fig. 6C), indicating that shaft synapses and their GRIP1 content were coregulated by ephrinB3. Therefore, it is possible that the localization of GRIP1

C

EphB2-Fc
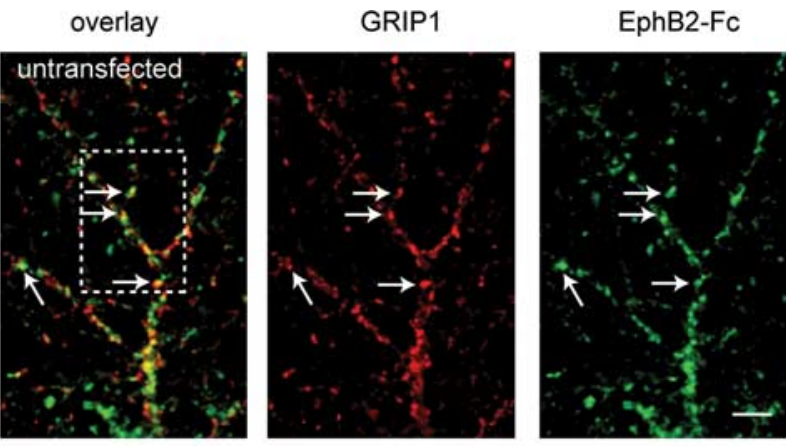

B
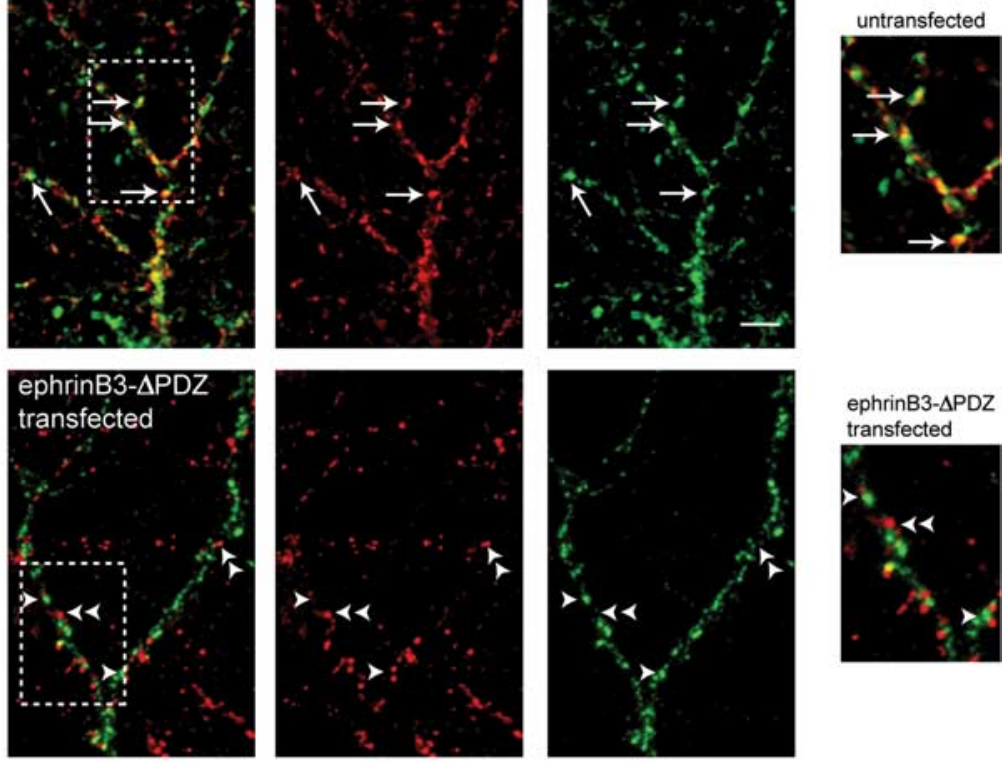

ephrinB3- $\triangle P D Z$ transfected
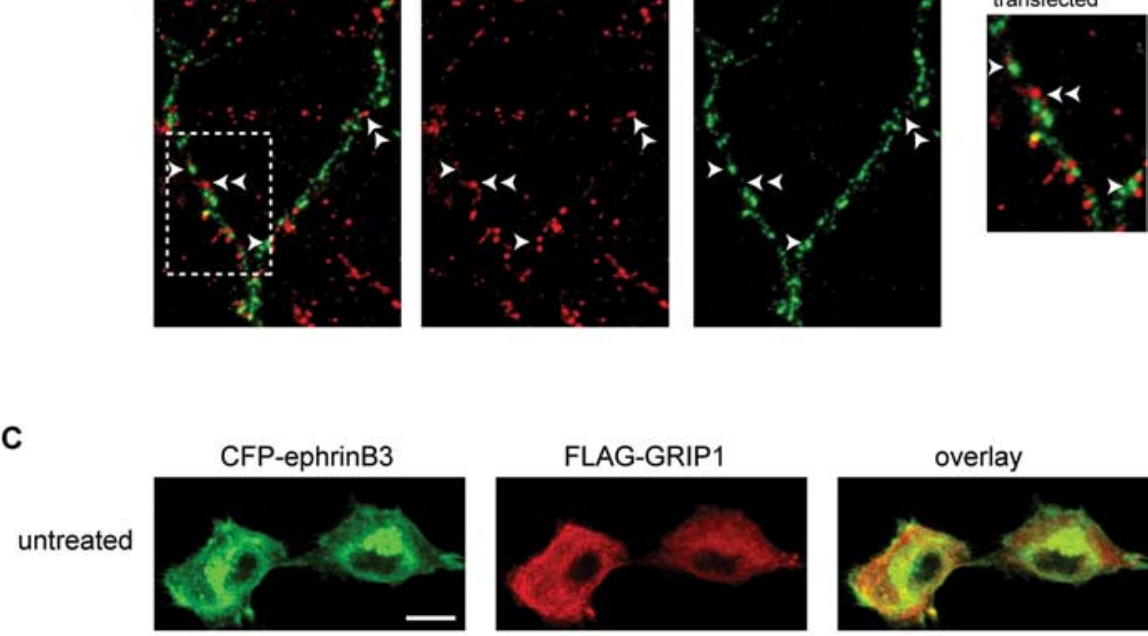

FLAG-GRIP1
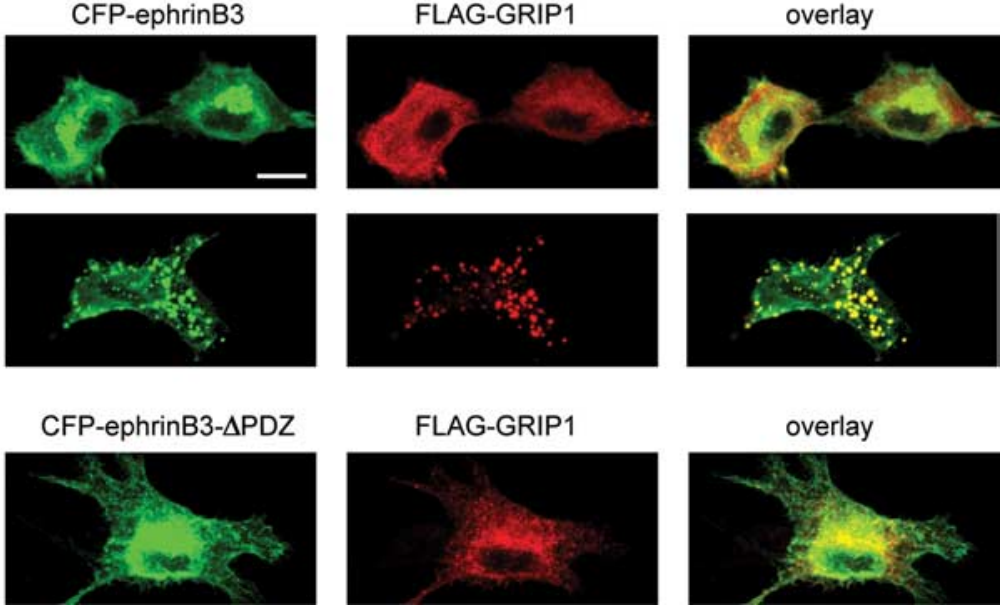

Figure 5. GRIP1 coclusters with ephrinB3. $\boldsymbol{A}$, Clustering of GRIP1 by EphB2-Fc in neuronal dendrites. Untransfected or ephrinB3- $\Delta$ PDZ-transfected neurons were incubated with EphB2-Fc that was preclustered with a FITC-conjugated secondary antibody against human $\mathrm{Fc}$, fixed, and immunostained for GRIP1. In untransfected neurons (top panels), large clusters of GRIP1 and EphB2-Fc were colocalized (arrows). In ephrinB3- $\triangle$ PDZ-transfected neurons (bottom panels), clusters of GRIP1 (double arrowheads) and EphB2-Fc (single arrowheads) are not colocalized. Scale bar, $10 \mu \mathrm{m} . \boldsymbol{B}$, Regions in the dashed rectangular box in $\boldsymbol{A}$ is shown at higher magnification. C, Coclustering of ephrinB3 and GRIP1 after EphB2 binding in HEK293 cells. HEK293 cells transiently expressing FLAG-GRIP1 and CFP-ephrinB3 were treated with EphB2-Fc before fixation and immunostaining. In untreated cells, the ephrinB3 signal was mostly diffuse and GRIP1 was found in small clusters. After EphB2-Fc treatment, ephrinB3 became highly clustered with GRIP1 in large membrane patches in ephrinB3-expressing cells, but not in ephrinB3- $\triangle P D Z-$ expressing cells. Scale bar, $10 \mu \mathrm{m}$.

in spines is not tightly controlled, and the changes in spine GRIP1 levels seen with ephrinB3 overexpression or knockdown are attributable to the sequestering or releasing of GRIP1 by shaft synapses.

\section{GRIP1 is required for ephrinB3-mediated shaft synapse formation}

We reasoned that, if GRIP1 is involved in ephrinB3-mediated shaft synapse formation, the phenotype of ephrinB3-siRNA might be reversed by the overexpression of GRIP1. Indeed, GRIP1 overexpression completely restored the mEPSC frequency 
A

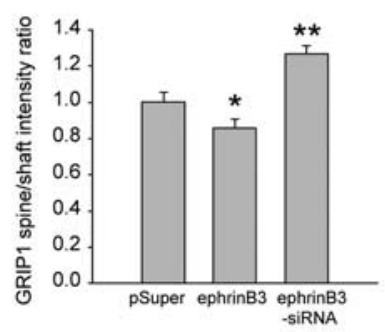

B

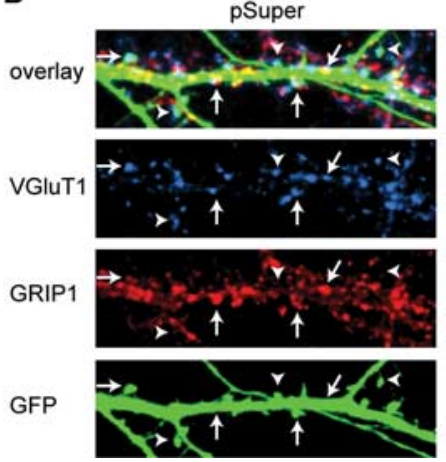

C

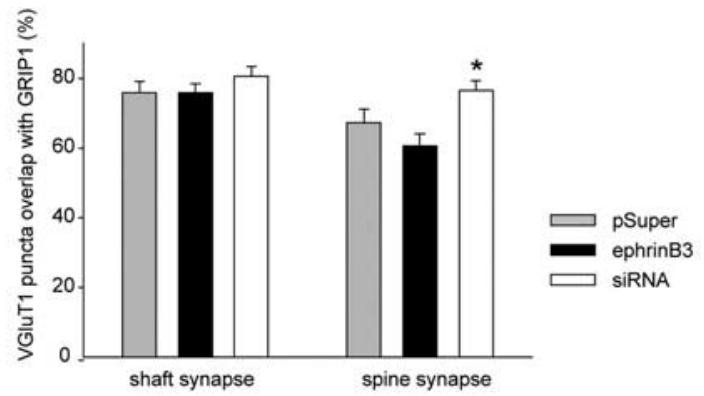

ephrinB3 overexpression
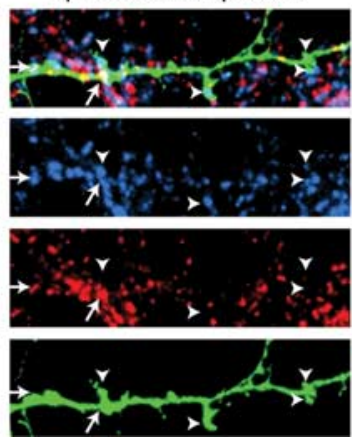

ephrinB3-siRNA

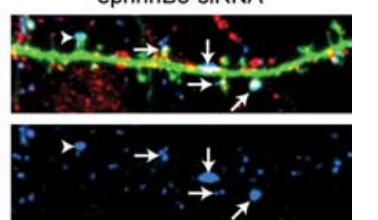

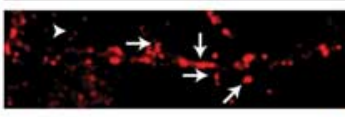

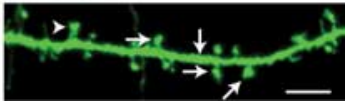

Figure 6. EphrinB3 expression regulates GRIP1 distribution in neurons. $A$, EphrinB3 influences the relative distributions of GRIP1 between dendritic shaft and spines. We separately quantified the intensities of GRIP1 signal from 100-150 $\mu \mathrm{m}$ stretches of dendritic shafts and from all individual spines along the same stretches of dendrites. Overexpression of ephrinB3 reduced the spine/shaft ratio of GRIP1 signal intensity, whereas ephrinB3 knockdown with ephrinB3-siRNA increased it ( $n=10$ cells for each group; $2-3$ dendritic branches per cell; $\left.{ }^{*} p<0.01 ;{ }^{* *} p<0.005\right)$. $B$, C, EphrinB3 directs GRIP1 to shaft glutamatergic synapses. Colocalization of VGluT1 and GRIP1 in both dendritic shafts and spines was measured. Manipulation of ephrinB3 expression levels did not change the proportion of shaft glutamatergic synapses that were GRIP1 positive ( $n=15$ cells per group; $2-3$ branches/cell; $p>0.5$ ). However, the number of spine synapses that were positive for GRIP1 was significantly increased by ephrinB3-siRNA ( ${ }^{*} p<0.05$ ). Arrows, GRIP1-positive synapses; arrowheads, GRIP1-negative synapses. Scale bars, $10 \mu \mathrm{m}$. All error bars indicate SEM.

in ephrinB3-siRNA neurons (Fig. 7A). To investigate whether this rescue of synaptic function is achieved exclusively through an increase in shaft synapse formation, we examined synapse density at spines and shafts with VGluT1 staining. The reduction of shaft synapse density by ephrinB3-siRNA was completely reversed by GRIP1 overexpression (Fig. $7 D, E, G$ ). Neither ephrinB3-siRNA nor GRIP1 overexpression affected spine synapse density (Fig. $7 F$ ).

The rescue of the ephrinB3-siRNA phenotype by GRIP1 overexpression suggests a role for GRIP1 in shaft synapse formation, but does not rule out the possibility that ephrinB3 and GRIP1 both promote synapse formation through parallel pathways. If GRIP1 is required for ephrinB3-induced shaft synapse formation, then knocking down GRIP1 expression should dampen the synaptogenic effect of ephrinB3 overexpression. We generated a GRIP1-siRNA construct that efficiently reduced GRIP1 expression (Fig. 7B). Synaptic PDZ proteins have been implicated in dendritic patterning (Charych et al., 2006). Specifically, knocking down GRIP1 for a prolonged period of time ( $4 \mathrm{~d}$ ) has been shown to affect dendrite morphogenesis (Hoogenraad et al., 2005). However, $1 \mathrm{~d}$ after GRIP1-siRNA transfection, we observed a significant reduction in GRIP1 expression in 13-14 DIV cultured hippocampal neurons without obvious morphological changes (supplemental Fig. 5, available at www.jneurosci.org as supplemental material). We therefore performed our experiments with $1 \mathrm{~d}$ GRIP1-siRNA expression. GRIP1 knockdown alone in neurons slightly reduced mEPSC frequency $(p=0.08)$ (Fig. $7 C$ ) without affecting its amplitude (data not shown). When coexpressed with ephrinB3, however, GRIP1-siRNA significantly diminished the increase in mEPSC frequency observed in ephrinB3overexpressing neurons (Fig. 7C). Quantification of glutamatergic synapse density with VGluT1 corroborated our electrophysiological results. Whereas GRIP1siRNA did not change synapse density significantly, it prevented the increase in shaft synapse formation by ephrinB3 overexpression (Fig. 7D-G). These results indicate that GRIP1 interaction with ephrinB3 is critically involved in shaft synapse formation.

\section{Discussion}

We have demonstrated here that postsynaptic ephrinB3, through its interaction with GRIP1, specifically induces shaft synapse formation. The observed lack of concurrent changes in spine synapses suggests that shaft and spine synapse formation are either two separable developmental steps, or two independent processes, of glutamatergic synapse formation. The formation of spine and shaft synapses may be determined by two distinct groups of synaptic proteins, whereas their maturation could involve similar synaptic proteins that are common for excitatory synapses (Marrs et al., 2001).

\section{EphrinB3 and synaptic function}

Until recently, research investigating roles of the ephrinB/EphB family in synaptic function has focused mainly on ephrinB-induced activation of postsynaptic EphB receptors, which is implicated in spine morphogenesis (Ethell et al., 2001; Henkemeyer et al., 2003; Ethell and Pasquale, 2005), glutamatergic synapse formation (Dalva et al., 2000; Kayser et al., 2006), and long-term potentiation (LTP) expression (Grunwald et al., 2001; Henderson et al., 2001). In the hippocampus, CA3 neurons express only Eph receptors (EphAs and EphBs), whereas CA1 neurons express both the receptors and ephrinB ligands (Bruckner et al., 1999). Forward and reverse signaling can therefore occur presynaptically or postsynaptically. Studies using genetically manipulated mice have established that ephrinB reverse signaling is involved in multiple forms of synaptic plasticity at both CA1 and CA3 region, although the involvement of postsynaptic ephrinB3 reverse signaling in CA3-CA1 plasticity is still under debate (Grunwald et al., 2004; Armstrong et al., 2006; Rodenas-Ruano et al., 2006).

The role of ephrinBs in synapse formation remains elusive. Basal synaptic transmission seems to be normal in ephrinB3-null mice, although there are apparent discrepancies between reports whether there are changes in synapse formation at an ultrastructural level (Grunwald et al., 2004; Rodenas-Ruano et al., 2006). We failed to detect changes in synaptic density or PSD size in the ephrinB3 ${ }^{-1-}$ mouse. The discrepancy may be attributable to differences among different lines of mutant mice as well as the amount of functional and structural compensation during development. Using siRNA-based protein knockdown methods, we 
were able to investigate the acute loss-offunction phenotype of ephrinB3 in hippocampal neurons. Our results reveal a novel mechanism for shaft synapse formation through ephrinB3 reverse signaling, which was confirmed by ultrastructural analysis in the ephrinB3 ${ }^{-1-}$ mouse. Activation of ephrinB reverse signaling has been shown recently to promote spine morphogenesis, likely mediated by ephrinB1 (Segura et al., 2007), suggesting that ephrinB isotypes play differential roles in spine and shaft synapse formation. In addition, EphBs have been shown to mediate spine synapse formation in cortical neurons (Kayser et al., 2006). The complementary roles of ephrinBs and EphBs in shaft and spine synapse formation provide a plausible mechanism by which distinct types of plasticity may differentially involve spine and shaft synapses.

\section{Involvement of GRIP1 in shaft synapse formation}

EphrinBs and GRIP (GRIP1 and GRIP2) are expressed in discrete regions of the CNS in developing embryos and adult animals. Although it has been established that all three ephrinB ligands interact with GRIP in vitro, based on coexpression pattern throughout the CNS, GRIP1 and ephrinB3 interaction has the greatest potential to be functionally relevant (Bruckner et al., 1999). It is well accepted that forward and reverse signaling activated by ephrinB/ EphB binding requires membrane clustering of ligand/receptor heteromers (Kullander and Klein, 2002). Whether PDZ protein interactions with the ligands or receptors are involved in clustering ligand/ receptor complexes and enhancing bidirectional signaling is not entirely clear. In heterologous cell expression systems, eph$\mathrm{rinB} / \mathrm{EphB}$ interaction is sufficient to activate bidirectional signaling (Holland et al., 1996), which allows contact-mediated re-

pulsion through endocytosis (Marston et al., 2003; Zimmer et al., 2003). Our results indicate that ephrinB3, when overexpressed in HEK293 cells, also exhibits synaptogenic activity. These effects could be attributable to high expression levels of ephrinB3 typical in heterologous cells, or interaction between ephrinB/EphB and PDZ proteins endogenous to these cell lines. In the hippocampus, mossy fiber-CA3 LTP requires trans-synaptic EphB/ephrinB signaling (Contractor et al., 2002; Armstrong et al., 2006). Interestingly, blocking postsynaptic EphB/GRIP1 interaction impaired the trans-synaptic induction of mossy fiber LTP (Contractor et al., 2002), suggesting that GRIP1 plays a role in promoting ephrinB/EphB complex clustering and subsequent intracellular signaling related to synaptic plasticity.

Our results provide additional evidence for a similar role of GRIP1 in ephrinB3-mediated shaft synapse formation: (1) fulllength ephrinB $3^{\star}$, but not ephrinB $3^{*}-\Delta \mathrm{PDZ}$, successfully rescued mEPSC frequency reduced by ephrinB3-siRNA; and (2) GRIP1
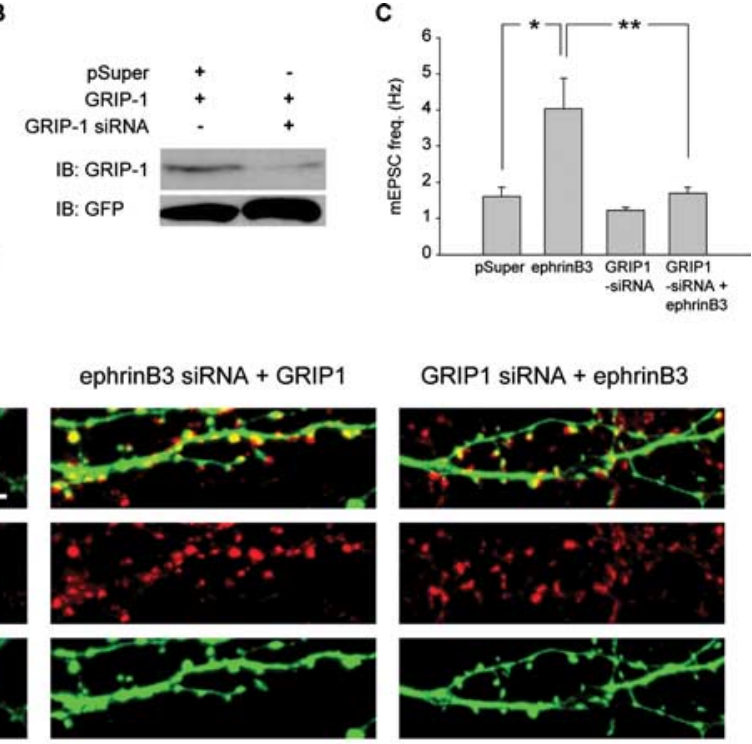

GRIP1 siRNA + ephrinB3

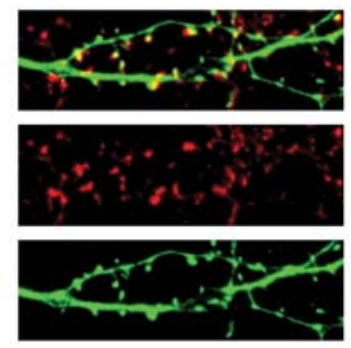

$\mathbf{F}$

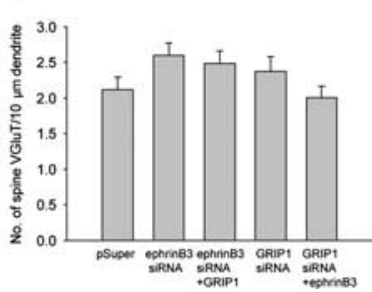

G

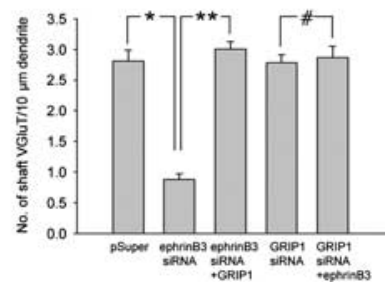

Figure 7. GRIP1 in critically involved in ephrinB3-mediated shaft synapse formation. $A$, GRIP1 overexpression restored mEPSC frequency reduced by ephrinB3-siRNA. GRIP1 overexpression alone did not affect mEPSC frequency (pSuper, $n=23 ; G R I P 1$ alone, 20, ephrinB3-siRNA, $n=10$; ephrinB3-siRNA + GRIP1, $n=30 ;{ }^{*} p<0.01$; $\left.{ }^{* *} p<0.005\right)$. B, Efficacy of GRIP1-siRNA. GRIP loading control. C, Effects of GRIP1 knockdown on ephrinB3-induced increase in mEPSC frequency. GRIP1-siRNA alone slightly reduced mEPSC frequency (pSuper, $n=11$; GRIP1-siRNA, $n=19 ; p=0.08$ ). Coexpression of GRIP1-siRNA with ephrinB3 prevented the mEPSC increase by ephrinB3 overexpression (ephrinB3, $n=12$; GRIP1-siRNA + ephrinB3, $n=28$; ${ }^{*} p<0.05$; 0 0.005). D-G, GRIP1 and shaft synapse formation. Shaft and spine synapse density was quantified with VGluT1 staining ( $=10$ cells . $\boldsymbol{E}$, The reduction of total synapse density caused by ephrinB3-siRNA was fully restored by GRIP1 overexpression density by ephrin $B 3$ overexpression ( $n=10$ cells per group; 3 branches/cell; ${ }^{\#} p>0.4$ ). $\boldsymbol{F}$, Spine synapse density was not affected significantly by any of the manipulations. $G$, The reduction of total synapse density caused by ephrinB3-siRNA was fully restored by GRIP1 overexpression $\left({ }^{*} p<10^{-12}\right.$; ${ }^{*} p<10^{-18}$ ). GRIP1-siRNA completely prevented the increase in synapse density by ephrinB3 overexpression $\left({ }^{\#} p>0.7\right)$. All error bars indicate SEM.

knockdown blocked the increase in shaft synapse formation by ephrinB3 overexpression. Based on these results, we propose a model for the induction of shaft synapse formation (Fig. 8A). Synaptogenesis on dendritic shafts is initiated by presynaptic EphB/postsynaptic ephrinB3 interaction, subsequent bidirectional signaling related to synaptogenesis is promoted by GRIP1mediated additional clustering of postsynaptic ephrinB3, likely through multimerization of GRIP1 (Im et al., 2003). This interaction allows presynaptic differentiation through EphB forward signaling, and postsynaptic maturation through ephrinB3 reverse signaling. In addition, GRIP1 multimers provide a platform of protein interaction further supporting the formation of multiple signaling molecule complexes including EphBs, AMPA receptors, and protein kinases (Bruckner et al., 1999). Overexpression of ephrinB3 recruits more GRIP1 into the dendritic shaft and promotes synapse formation (Fig. $8 \mathrm{~B}$ ). Conversely, reducing ephrinB3 expression by siRNA knockdown reduces the availabil- 
A
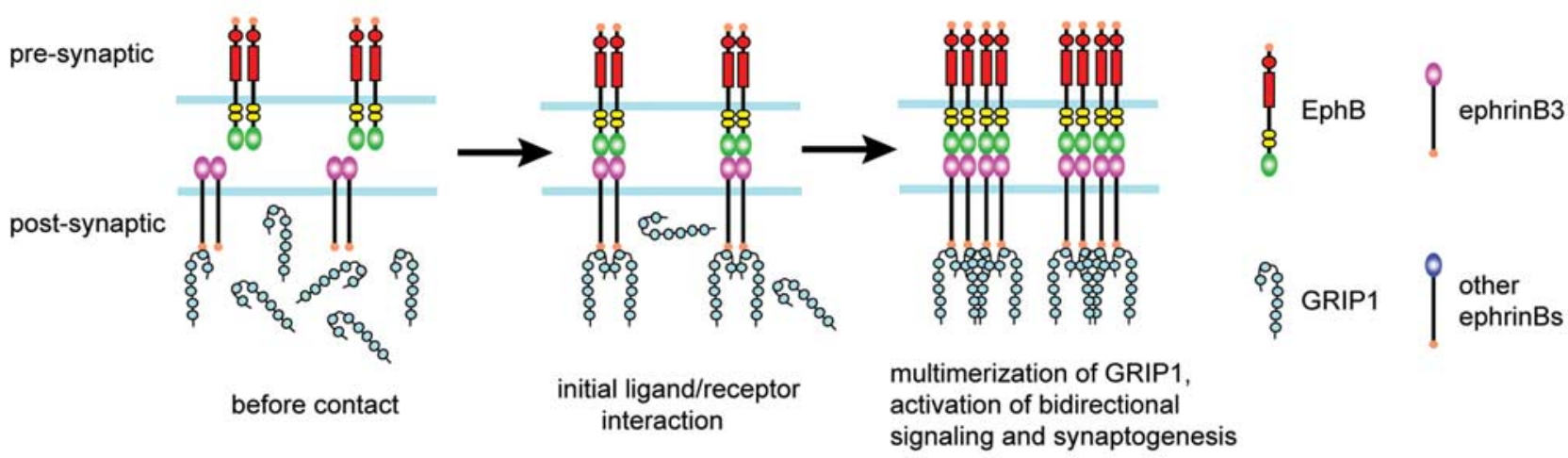

B

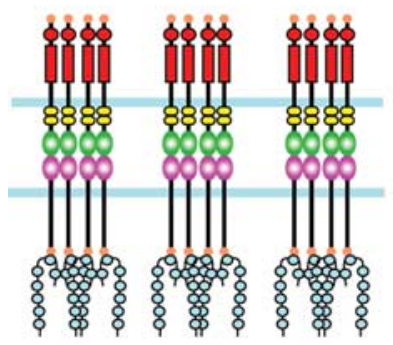

ephrinB3 overexpression increases synapse formation
C

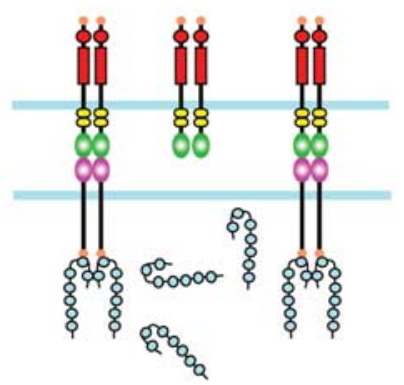

ephrinB3 knockdown decreases synapse formation
D

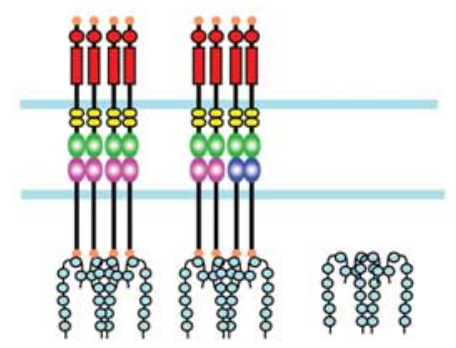

GRIP1 overexpression rescues ephrinB3 knockdown phenotype by multimerization and recruitment of other ephrinB ligands
E

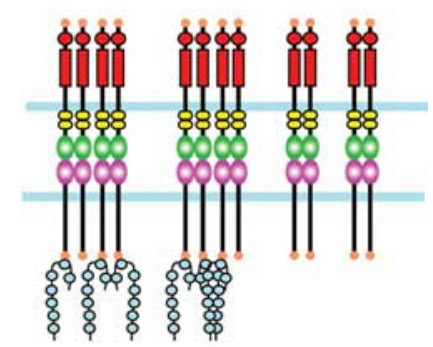

GRIP1 knockdown prevents ephrinB3 overexpression induced synaptogenesis

Figure 8. A model for postsynaptic ephrinB3-mediated shaft synapse formation. For detailed explanations of $\boldsymbol{A}-\boldsymbol{E}$, see Discussion.

ity of both ephrinB3 and GRIP1 in dendritic shafts and therefore reduces shaft synapse density (Fig. 8C). Overexpression of GRIP1 rescues ephrinB3-siRNA phenotype by two possible mechanisms (Fig. 8D). First, GRIP1 forms large intracellular aggregates when expressed at high levels (Bruckner et al., 1999), which could be more effective in recruiting and clustering the remaining low levels of ephrinB3. Second, other ephrinB isoforms, such as ephrinB2, are also expressed in hippocampal neurons (Grunwald et al., 2001). Overexpression of GRIP1 may incorporate these ephrinBs into ephrinB3 signaling complexes. The involvement of GRIP1 in dendrite morphogenesis restricted us to examine the effect of GRIP1-siRNA on synaptogenesis after only $1 \mathrm{~d}$ of knockdown. This may explain the lack of GRIP1-siRNA effect on existing synapses. However, GRIP1-siRNA blocked the ephrinB3induced increase in shaft synapse formation. This not only demonstrates that GRIP1 expression is significantly reduced even after $1 \mathrm{~d}$ of siRNA expression, but also suggests that, in neurons, bidirectional signaling of ephrinB3/EphB pertaining shaft synapse formation requires GRIP1 interaction with postsynaptic ephrinB3 (Fig. 8E). The involvement of GRIP1 in both dendrite morphogenesis (Hoogenraad et al., 2005) and synapse formation also imply that these two processes are tightly coupled during neural development.

\section{Functional significance of shaft synapses}

A prevailing view for shaft synapse function in spiny neurons is that it serves as a precursor for spine synapses during brain development and activity-dependent synaptogenesis (Harris, 1999; Ethell and Pasquale, 2005). However, enduring changes in the number of shaft synapses have been observed $8 \mathrm{~h}$ after LTP in- duction (Chang and Greenough, 1984), $24 \mathrm{~h}$ after passive avoidance training (Nikolakopoulou et al., 2006), and weeks after the onset of specific emotional or visual experiences (Jones et al., 1997; Helmeke et al., 2001). Given that new spine formation occurs within hours of LTP induction (Engert and Bonhoeffer, 1999; Maletic-Savatic et al., 1999), and that the time course required to achieve the proposed shaft to spine synapse transition during activity-dependent synaptogenesis is relatively short (30 min) (Nikonenko et al., 2003), it seems unlikely that the persistent changes in shaft synapse number observed in these studies merely reflect an early transitional stage of synaptogenesis. In addition, in vivo imaging followed by serial section electron microscopy revealed that in the adult neocortex spine growth precedes synaptic contact (Knott et al., 2006). The changes in shaft synapse density that others and we observed occur without obvious concurrent modifications of spine synapses. For instance, epileptiform activity induces a net loss of synapses on spines but not on shafts, whereas activity blockade induces a specific loss of shaft synapses (Zha et al., 2005). High-frequency stimulation that induces LTP increases shaft synapses by $33 \%$ without affecting spine synapse number (Lee et al., 1980). An increase in the shaft synapse population is associated with the maintenance phase of LTP (Geinisman et al., 1996). Long-lasting independent modification of shaft synapses also occurs after behavioral learning (Helmeke et al., 2001; Nikolakopoulou et al., 2006). We also observed in this study changes in shaft synapses that are not associated with spine synapses both in vitro and in vivo. Together, it seems that shaft and spine synapse formation might be completely independent and may serve different functions. Protein synthesis machinery (i.e., polyribosomes) is found associated 
with spine as well as shaft synapses (Steward and Falk, 1986), implying that both types of synapses are poised for local protein synthesis-dependent synaptic plasticities. The geometry of spines compartmentalizes electrical and chemical signals generated from spine synapses, allowing synapse-specific modifications. In contrast, synaptic contacts made directly on dendritic shafts may be more efficacious than spine synapses (Rall, 1970; Shepherd et al., 1989; Rusakov et al., 1998) and may have greater influence on dendritic signal integration. Additional studies on how manipulations of shaft synapses impact interneuronal communication and animal behaviors should elucidate the specific functions of the shaft synapse.

\section{References}

Anderson JC, Martin KA (2006) Synaptic connection from cortical area V4 to V2 in macaque monkey. J Comp Neurol 495:709-721.

Armstrong JN, Saganich MJ, Xu NJ, Henkemeyer M, Heinemann SF, Contractor A (2006) B-ephrin reverse signaling is required for NMDAindependent long-term potentiation of mossy fibers in the hippocampus. J Neurosci 26:3474-3481.

Biederer T, Sara Y, Mozhayeva M, Atasoy D, Liu X, Kavalali ET, Sudhof TC (2002) SynCAM, a synaptic adhesion molecule that drives synapse assembly. Science 297:1525-1531.

Boyer C, Schikorski T, Stevens CF (1998) Comparison of hippocampal dendritic spines in culture and in brain. J Neurosci 18:5294-5300.

Bozhilova-Pastirova A, Ovtscharoff W (1996) Structure of the synaptic junctions in the rat sensorimotor cortex. Freeze-etching study of axodendritic synapses. Eur J Morphol 34:363-373.

Bruckner K, Pablo Labrador J, Scheiffele P, Herb A, Seeburg PH, Klein R (1999) EphrinB ligands recruit GRIP family PDZ adaptor proteins into raft membrane microdomains. Neuron 22:511-524.

Chang FL, Greenough WT (1984) Transient and enduring morphological correlates of synaptic activity and efficacy change in the rat hippocampal slice. Brain Res 309:35-46.

Charych EI, Akum BF, Goldberg JS, Jornsten RJ, Rongo C, Zheng JQ, Firestein BL (2006) Activity-independent regulation of dendrite patterning by postsynaptic density protein PSD-95. J Neurosci 26:10164-10176.

Contractor A, Rogers C, Maron C, Henkemeyer M, Swanson GT, Heinemann SF (2002) Trans-synaptic Eph receptor-ephrin signaling in hippocampal mossy fiber LTP. Science 296:1864-1869.

Dailey ME, Smith SJ (1996) The dynamics of dendritic structure in developing hippocampal slices. J Neurosci 16:2983-2994.

Dalva MB, Takasu MA, Lin MZ, Shamah SM, Hu L, Gale NW, Greenberg ME (2000) EphB receptors interact with NMDA receptors and regulate excitatory synapse formation. Cell 103:945-956.

Dong H, O’Brien RJ, Fung ET, Lanahan AA, Worley PF, Huganir RL (1997) GRIP: a synaptic PDZ domain-containing protein that interacts with AMPA receptors. Nature 386:279-284

Dong H, Zhang P, Song I, Petralia RS, Liao D, Huganir RL (1999) Characterization of the glutamate receptor-interacting proteins GRIP1 and GRIP2. J Neurosci 19:6930-6941.

Engert F, Bonhoeffer T (1999) Dendritic spine changes associated with hippocampal long-term synaptic plasticity. Nature 399:66-70.

Ethell IM, Pasquale EB (2005) Molecular mechanisms of dendritic spine development and remodeling. Prog Neurobiol 75:161-205.

Ethell IM, Irie F, Kalo MS, Couchman JR, Pasquale EB, Yamaguchi Y (2001) EphB/syndecan-2 signaling in dendritic spine morphogenesis. Neuron 31:1001-1013.

Fiala JC, Harris KM (1999) In: Dendritic structure (Stuart G, Spruston N, Hausser M, eds), pp 1-34. Oxford: Oxford UP.

Fiala JC, Feinberg M, Popov V, Harris KM (1998) Synaptogenesis via dendritic filopodia in developing hippocampal area CA1. J Neurosci 18:8900-8911.

Geinisman Y, Detoledo-Morrell L, Morrell F, Persina IS, Beatty MA (1996) Synapse restructuring associated with the maintenance phase of hippocampal long-term potentiation. J Comp Neurol 368:413-423.

Graf ER, Zhang X, Jin SX, Linhoff MW, Craig AM (2004) Neurexins induce differentiation of GABA and glutamate postsynaptic specializations via neuroligins. Cell 119:1013-1026.

Grunwald IC, Korte M, Wolfer D, Wilkinson GA, Unsicker K, Lipp HP, Bon- hoeffer T, Klein R (2001) Kinase-independent requirement of EphB2 receptors in hippocampal synaptic plasticity. Neuron 32:1027-1040.

Grunwald IC, Korte M, Adelmann G, Plueck A, Kullander K, Adams RH, Frotscher M, Bonhoeffer T, Klein R (2004) Hippocampal plasticity requires postsynaptic ephrinBs. Nat Neurosci 7:33-40.

Harris KM (1999) Structure, development, and plasticity of dendritic spines. Curr Opin Neurobiol 9:343-348.

Harris KM, Jensen FE, Tsao B (1992) Three-dimensional structure of dendritic spines and synapses in rat hippocampus (CA1) at postnatal day 15 and adult ages: implications for the maturation of synaptic physiology and long-term potentiation. J Neurosci 12:2685-2705.

Helmeke C, Ovtscharoff Jr W, Poeggel G, Braun K (2001) Juvenile emotional experience alters synaptic inputs on pyramidal neurons in the anterior cingulate cortex. Cereb Cortex 11:717-727.

Henderson JT, Georgiou J, Jia Z, Robertson J, Elowe S, Roder JC, Pawson T (2001) The receptor tyrosine kinase EphB2 regulates NMDA-dependent synaptic function. Neuron 32:1041-1056.

Henkemeyer M, Itkis OS, Ngo M, Hickmott PW, Ethell IM (2003) Multiple EphB receptor tyrosine kinases shape dendritic spines in the hippocampus. J Cell Biol 163:1313-1326.

Hering H, Sheng M (2001) Dendritic spines: structure, dynamics and regulation. Nat Rev Neurosci 2:880-888.

Holland SJ, Gale NW, Mbamalu G, Yancopoulos GD, Henkemeyer M, Pawson T (1996) Bidirectional signalling through the EPH-family receptor Nuk and its transmembrane ligands. Nature 383:722-725.

Hoogenraad CC, Milstein AD, Ethell IM, Henkemeyer M, Sheng M (2005) GRIP1 controls dendrite morphogenesis by regulating EphB receptor trafficking. Nat Neurosci 8:906-915.

Im YJ, Park SH, Rho SH, Lee JH, Kang GB, Sheng M, Kim E, Eom SH (2003) Crystal structure of GRIP1 PDZ6-peptide complex reveals the structura basis for class II PDZ target recognition and PDZ domain-mediated multimerization. J Biol Chem 278:8501-8507.

Jones TA, Klintsova AY, Kilman VL, Sirevaag AM, Greenough WT (1997) Induction of multiple synapses by experience in the visual cortex of adult rats. Neurobiol Learn Mem 68:13-20.

Katz B, Miledi R (1968) The role of calcium in neuromuscular facilitation. J Physiol (Lond) 195:481-492.

Kayser MS, McClelland AC, Hughes EG, Dalva MB (2006) Intracellular and trans-synaptic regulation of glutamatergic synaptogenesis by EphB receptors. J Neurosci 26:12152-12164.

Klein R (2004) Eph/ephrin signaling in morphogenesis, neural development and plasticity. Curr Opin Cell Biol 16:580-589.

Knott GW, Holtmaat A, Wilbrecht L, Welker E, Svoboda K (2006) Spine growth precedes synapse formation in the adult neocortex in vivo. Nat Neurosci 9:1117-1124.

Kullander K, Klein R (2002) Mechanisms and functions of Eph and ephrin signalling. Nat Rev Mol Cell Biol 3:475-486.

Lee KS, Schottler F, Oliver M, Lynch G (1980) Brief bursts of highfrequency stimulation produce two types of structural change in rat hippocampus. J Neurophysiol 44:247-258.

Maletic-Savatic M, Malinow R, Svoboda K (1999) Rapid dendritic morphogenesis in CA1 hippocampal dendrites induced by synaptic activity. Science 283:1923-1927.

Marrs GS, Green SH, Dailey ME (2001) Rapid formation and remodeling of postsynaptic densities in developing dendrites. Nat Neurosci 4:1006-1013.

Marston DJ, Dickinson S, Nobes CD (2003) Rac-dependent transendocytosis of ephrinBs regulates Eph-ephrin contact repulsion. Nat Cell Biol 5:879-888.

Moeller ML, Shi Y, Reichardt LF, Ethell IM (2006) EphB receptors regulate dendritic spine morphogenesis through the recruitment/phosphorylation of focal adhesion kinase and RhoA activation. J Biol Chem 281:1587-1598

Nam CI, Chen L (2005) Postsynaptic assembly induced by neurexinneuroligin interaction and neurotransmitter. Proc Natl Acad Sci USA 102:6137-6142.

Nikolakopoulou AM, Davies HA, Stewart MG (2006) Passive avoidance training decreases synapse density in the hippocampus of the domestic chick. Eur J Neurosci 23:1054-1062.

Nikonenko I, Jourdain P, Muller D (2003) Presynaptic remodeling contributes to activity-dependent synaptogenesis. J Neurosci 23:8498-8505.

Penzes P, Johnson RC, Sattler R, Zhang X, Huganir RL, Kambampati V, Mains RE, Eipper BA (2001) The neuronal Rho-GEF Kalirin-7 interacts 
with PDZ domain-containing proteins and regulates dendritic morphogenesis. Neuron 29:229-242.

Penzes P, Beeser A, Chernoff J, Schiller MR, Eipper BA, Mains RE, Huganir RL (2003) Rapid induction of dendritic spine morphogenesis by transsynaptic ephrinB-EphB receptor activation of the Rho-GEF kalirin. Neuron 37:263-274.

Rall W (1970) Cable properties of dendrities and effects of synaptic location. In: Excitatory synaptic mechanisms (Andersen P, Jensen JKS, eds), pp 175-187. Oslo: Universitets Forlaget.

Rodenas-Ruano A, Perez-Pinzon MA, Green EJ, Henkemeyer M, Liebl DJ (2006) Distinct roles for ephrinB3 in the formation and function of hippocampal synapses. Dev Biol 292:34-45.

Rusakov DA, Harrison E, Stewart MG (1998) Synapses in hippocampus occupy only $1-2 \%$ of cell membranes and are spaced less than half-micron apart: a quantitative ultrastructural analysis with discussion of physiological implications. Neuropharmacology 37:513-521.

Scheiffele P, Fan J, Choih J, Fetter R, Serafini T (2000) Neuroligin expressed in nonneuronal cells triggers presynaptic development in contacting axons. Cell 101:657-669.

Segura I, Essmann CL, Weinges S, Acker-Palmer A (2007) Grb4 and GIT1 transduce ephrinB reverse signals modulating spine morphogenesis and synapse formation. Nat Neurosci 10:301-310.

Shepherd GM, Woolf TB, Carnevale NT (1989) Comparisons between active properties of distal dendritic branches and spines: implications for neuronal computation. J Cogn Neurosci 1:273-286.

Steward O, Falk PM (1986) Protein-synthetic machinery at postsynaptic sites during synaptogenesis: a quantitative study of the association between polyribosomes and developing synapses. J Neurosci 6:412-423.

Trachtenberg JT, Chen BE, Knott GW, Feng G, Sanes JR, Welker E, Svoboda K (2002) Long-term in vivo imaging of experience-dependent synaptic plasticity in adult cortex. Nature 420:788-794.

Tremblay ME, Riad M, Bouvier D, Murai KK, Pasquale EB, Descarries L, Doucet G (2007) Localization of EphA4 in axon terminals and dendritic spines of adult rat hippocampus. J Comp Neurol 501:691-702.

Vaughan DW, Peters A (1973) A three-dimensional study of layer I of the rat parietal cortex. J Comp Neurol 149:355-370.

Yokoyama N, Romero MI, Cowan CA, Galvan P, Helmbacher F, Charnay P, Parada LF, Henkemeyer M (2001) Forward signaling mediated by ephrin-B3 prevents contralateral corticospinal axons from recrossing the spinal cord midline. Neuron 29:85-97.

Yuste R, Bonhoeffer T (2001) Morphological changes in dendritic spines associated with long-term synaptic plasticity. Annu Rev Neurosci 24:1071-1089.

Yuste R, Bonhoeffer T (2004) Genesis of dendritic spines: insights from ultrastructural and imaging studies. Nat Rev Neurosci 5:24-34.

Zha XM, Green SH, Dailey ME (2005) Regulation of hippocampal synapse remodeling by epileptiform activity. Mol Cell Neurosci 29:494-506.

Zimmer M, Palmer A, Kohler J, Klein R (2003) EphB-ephrinB bidirectional endocytosis terminates adhesion allowing contact mediated repulsion. Nat Cell Biol 5:869-878.

Zucker RS, Regehr WG (2002) Short-term synaptic plasticity. Annu Rev Physiol 64:355-405. 